Portland State University

PDXScholar

12-8-1995

\title{
A Study Comparing Musical Abilities of Stutterers and Nonstutterers
}

Megan Creswell

Portland State University

Follow this and additional works at: https://pdxscholar.library.pdx.edu/open_access_etds

Part of the Speech and Rhetorical Studies Commons

Let us know how access to this document benefits you.

\section{Recommended Citation}

Creswell, Megan, "A Study Comparing Musical Abilities of Stutterers and Nonstutterers" (1995).

Dissertations and Theses. Paper 5250.

https://doi.org/10.15760/etd.7123

This Thesis is brought to you for free and open access. It has been accepted for inclusion in Dissertations and Theses by an authorized administrator of PDXScholar. Please contact us if we can make this document more accessible: pdxscholar@pdx.edu. 


\section{THESIS APPROVAE}

The abstract and thesis of Megan Creswell for the Master of Science in Speech Communication: Speech and Hearing Sciences were presented December 8, 1995, and accepted by the thesis committee and the/departmeht.

COMMITTEE APPROVALS :

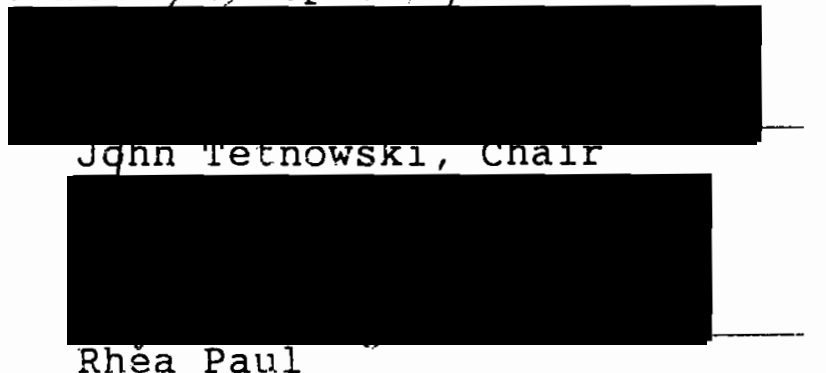

DEPARTMENT APPROVAL :

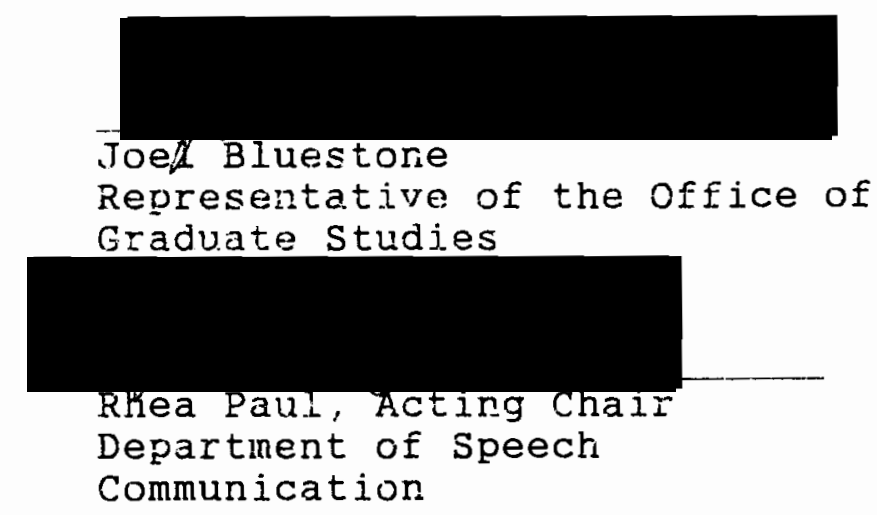

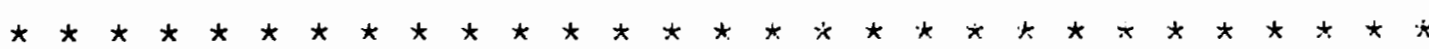

ACCEPTED FOR PORTLAND STATE UNIVERSITY BY THE LIBRARY 


\section{ABSTRACT}

An abstract of the thesis of Megan Creswell for the Master of Science in Speech Communication: Speech and Hearing Sciences presented December 8, 1995 .

Title: A Study Comparing Musical Abilities of Stutterers and Nonstutterers.

Rhythm is a feature of both music and speech that has been successfully used in the treatment of speech disorders, particularly stuttering, for many years. The successful use of rhythm in the treatment of dysfluencies of speech may be due to stutterers' perceptual deficiencies in music and rhythm abilities. Research supports the view that there are differences between stutterers and nonstutterers in timing and rhythmic capabilities. This study, therefore, sought to determine whether there was a difference between the perceptual musical abilities of stutterers versus nonstutterers as measured by the Seashore Measures of Musical Talents, Revised (1960).

Data collected were from two groups of subjects consisting of 10 stutterers and 10 nonstutterers. Groups were matched according to age and gender. Subjects were examined using the Seashore, a test which measures levels of musical ability in the areas of pitch, time, timbre, rhythm, tonal memory and loudness. Subjects listened to recorded tones on a cassette tape player while marking their answers on IBM answer sheets. For example, in the pitch test, fifty 
pairs of tones on a cassette tape were presented. The subject determined whether the second tone presented was higher (H) or lower (L) than the first. A mark was made in either the column headed $\mathrm{H}$ or L. Each subtest proceeded in a similar manner. A total score of level of musical function was then determined from the scores of each subtest. Total scores and individual subtest scores were compared using the Wilcoxon Signed Ranks Test for Paired Observations (.05 level of significance) to determine whether there were overall differences between groups or differences between groups in specific areas.

Results show stutterers scoring significantly lower in the rhythm subtest $(P=.0077)$ and in total scores $(P=.0244)$. Other significant differences were not found. These results might suggest that further support should be given to the study of actual treatment(s) using rhythmic concepts. Since no studies exist that investigate the theory that stutterers have perceptual rhythmic/timing deficiencies, studies such as this would provide normative data on musical abilities of stutterers, with emphasis on rhythm and timing abilities. 
A STUDY COMPARING MUSICAL ABILITIES OF STUTTERERS AND NONSTUTTERERS

by

MEGAN CRESWELL

A thesis submitted in partial fulfillment of the requirements for the degree of

MASTER OF SCIENCE

in

SPEECH COMMUNICATION:

SPEECH \& HEARING SCIENCES

Portland State University

1996 


\section{ACKNOWLEDGMENTS}

I would like to extend my sincerest gratitude and appreciation to the members of my thesis committee, Dr. John Tetnowski, Dr. Rhea Paul, and Dr. Joel Bluestone. A special note of thanks is extended to Dr. Tetnowski for his committed effort and valuable input throughout the duration of this project, even when knee surgery kept him from his usual academic schedule.

My husband, Sig Anderson, did his best to help manage the household, provide much support, and thus maintain my sanity. My daughters, Tovi and Kaeley Anderson, kept me grounded in reality throughout this graduate school process and have been real troopers. Thanks you three, you're great! 
TABLE OF CONTENTS

PAGE

ACKNOWLEDGEMENTS

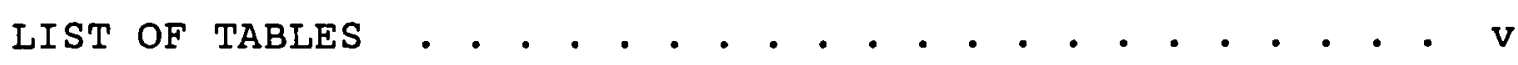
CHAPTER

I INTRODUCTION AND PURPOSE STATEMENT . . . . . 1 Introduction . . . . . . . . . . . . 1

Statement of Purpose . . . . . . . . 3

Definition of Terms . . . . . . . . 5

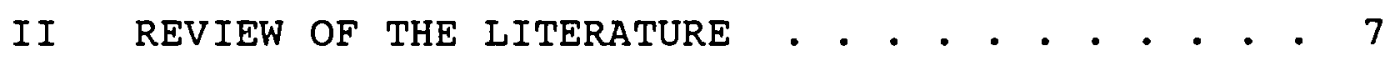

Rhythm in stuttering . . . . . . . . 7

Characteristics of people who stutter History of rhythmic techniques

Studies Investigating Rhythm

II METHODS AND PROCEDURES . . . . . . . . . . 22

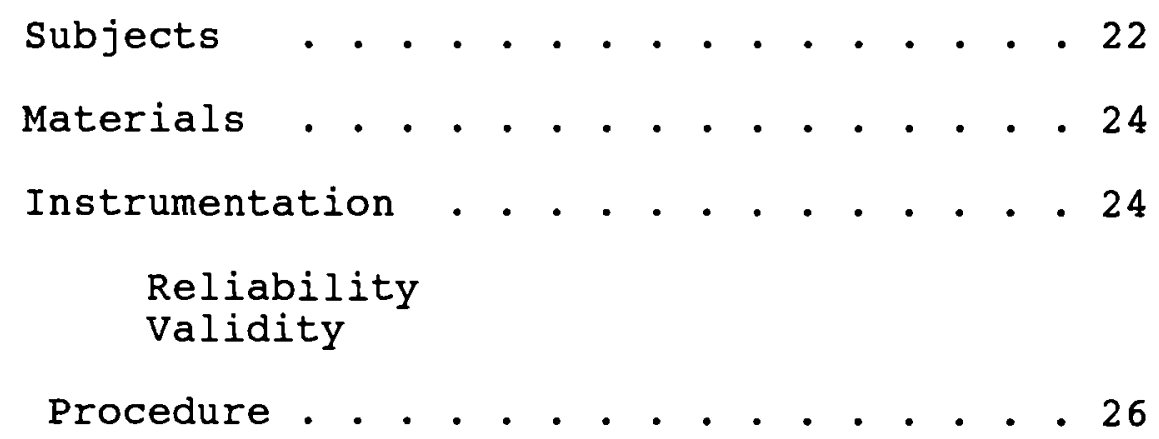

IV RESULTS AND DISCUSSION . . . . . . . . . . 29

Results . . . . . . . . . . . . . 29

Discussion . . . . . . . . . . . 31 
V SUMMARY AND IMPLICATIONS • • • • • • • • • • 36

Summary • • • • • • • . • • • • • • • 36

Implications . • . . . . • • • • • 37

Research

Clinical

REFERENCES . . . . . . . . . . . . . . . . . . . . . . 40 


\section{LIST OF TABLES}

TABLE

PAGE

1 Severity Rating for the Group Labeled

Stutterers According to Riley's

Stuttering Severity Instrument (SSI) • . . 23

2 Group Mean Scores for Subtests and Total

Scores . . . . . . . . . . . . 30

3 Wilcoxan Matched Pairs Signed Ranks Test

Comparing Perceptual Musical Ability

of Stutterers and Nonstutterers . . . . 31 


\section{CHAPTER I}

\section{INTRODUCTION AND STATEMENT OF PURPOSE}

\section{Introduction}

There are many aspects of speech that are also shared with music. Numerous speech and language disorders have been successfully treated using musical activities as part of an intervention program. Melodic Intonation Therapy (Sparks \& Holland, 1976) and combinations of music and rhythmic instruction have been used as therapeutic interventions for neurologically impaired patients with expressive speech disorders (Cohen \& Masse, 1993). Music therapy has been used with preschoolers to promote verbalization (Cassidy, 1992) and articulation has been treated using music activities to increase intelligibility (Zoller, 1991).

Rhythm is a feature of music that has been used in the treatment of speech disorders, particularly stuttering, for a number of years. For over a century it has been known that rhythm dramatically increases fluency whenever stutterers speak in a regular pattern (Beech, 1967; Brady \& Brady, 1972; Ham, 1986; Jones \& Azrin, 1969; Meyer \& Mair, 1963; Van Dantzig, 1940; Wingate, 1976;). Ham (1986) states that rhythm is actually reported to be the most effective 
and rapid method for inducing fluency in stuttered speech.

In spite of this, stuttering has only been treated using rhythmical aspects the last thirty years or so (Ham, 1986). Rhythm has rarely been used as part of a complete musical intervention approach in the treatment of stuttering, as it has with the treatment of neurological impairments and other speech disorders. It is possible that rhythmic instruction by itself, or in conjunction with basic singing techniques, such as correct breathing and precise diction, could improve speech production and/or fluency more effectively when used independently or with other treatment approaches .

Perhaps music components, such as rhythm, are successful in treating dysfluencies of speech because of stutterers' perceptual deficiencies in music and rhythmic abilities. No studies have been found that investigate this theory, and no musical or rhythmical pretesting prior to a stuttering intervention program has been utilized to determine if these deficits exist. Also, no studies have been found that compare perception and/or production of rhythm or general musical ability and stuttering. Studies have been done that show other stutterer-nonstutterer differences (Andrews et al., 1983) concerning intelligence, speech development, central auditory function, sensory-motor response, and electromyograph (EMG) activity and duration (Van Lieshout, Peters, Starkweather, \& Hulstijn, 1993). 
Other weaknesses have been found in stutterers' motoric capabilities such as onset sequencing of certain oral muscles (Guitar, Guitar, Neilson, O'Dwyer, \& Andrews, 1988), and high levels of muscle activity (Murray, Empson, \& Weaver, 1987). Since research supports the view that there are differences between stutterers and nonstutterers in timing and rhythmic capabilities (Cooper \& Allen, 1977; Harrington, 1988; Kent, 1983) this study seeks to compare perceptual rhythmical, and general musical abilities of stutterers, with those skills of matched nonstutterers.

Statement of Purpose

The purpose of this study is to determine whether there is a difference between the perceptual musical abilities of stutterers versus the perceptual musical abilities of nonstutterers as measured by the Seashore Measures of Musical Talents, Revised (1960). Rhythm and timing are two aspects of music common to speech and are measured by the Seashore test.

If a significant perceptual difference is shown to exist, this may assist researchers in the understanding of what is involved in increasing speech fluency of stutterers. It is possible that deficits occurring in the perception of rhythm and timing might be related to production deficits of rhythm and timing. This needs to be studied more extensively and might lead researchers to develop and study more fluency treatment programs consisting of specific 
rhythm and timing techniques.

The research hypothesis states that there is a significant difference in perceptual musical abilities between stutterers and nonstutterers, with stutterers scoring lower on total scores and subtest scores of the Seashore Measures of Musical Talents, Revised, than nonstutterers. The null hypothesis states therefore, that stutterers' and nonstutterers' scores on the Seashore Measures of Musical Talents, Revised, are not significantly different, indicating no difference in perceptual musical abilities between the two groups. 


\section{Definition of Terms}

The following are definitions of terms used for this study.

1. Dysfluency: A disruption in fluency of verbal expression which is characterized by involuntary, audible or silent repetitions or prolongations in the utterance of short speech elements, namely: sounds, syllables, and words of one syllable. These disruptions usually occur frequently or are marked in character and are not readily controllable (Wingate, 1964).

2. Fluency: The speech of people who do not stutter; the nonstuttered speech of stutterers (Ham, 1990).

3. Loudness: The strength of a musical tone (Seashore, 1960).

4. Musical ability: Those capabilities which are essential for the hearing, the feeling, the understanding, and for some form of expression of music, with a resulting drive or urge toward music (Seashore, 1919).

5. Pitch: A term referring to the high-low quality of a musical sound. The pitch is determined by the frequency of the tone, or the number of vibrations per second (Apel\& Daniel, 1960).

6. Rhythm: An aspect of rate and continuity that is determined by the pattern of stress and unstress 
in syllable production. Stress points in utterances are patterned according to customs of a particular language (Ham, 1990).

7. Stuttering: See dysfluency.

8. Timbre: The peculiar quality of a tone as sounded by a given instrument or voice. The term, therefore, indicates the difference between two tones of the same pitch, duration, and intensity (Apel \& Daniel, 1960).

9. Time: The metrical duration of a note or rest (Seashore, 1960).

10. Tonal Memory: The ability to identify differences between tonal sequences (Seashore, 1960). 
CHAPTER II

REVIEW OF THE LITERATURE

Rhythm in stuttering

Our speech has its own inherent, individual cadence but is not evenly paced. Neurophysiological aspects (limitations of neuron firing rate, impulse transmission speed, and the response and rest cycle of muscle fibers) and prosodic features contribute to individual patterns of speech; a natural speech rhythm. What is called rhythm in stuttering treatment is an artificial rhythm and generally involves the timing of speech in an absolutely regular pattern at a slower rate than normal speech. Singing, shadowing, unison speech, simultaneous talking and writing, metronome, etc. are all examples of rhythm methods that produce a timing pattern (Ham, 1986).

Rhythm is generally known to be one of the most effective and fastest way to bring about fluency in stuttered speech. It may be for this reason that it has been associated with "quacks" as a "guaranteed quick cure" for stutterers (Bluemel, 1960). Others believe it works simply as a distraction device (Barber, 1940; Bloodstein, 1949 ) and that it distorts speech into unusable patterns Bluemel, 1960). Many professionals still reject the use of 
rhythm in treating stuttering, but in Van Riper's (1973) opinion, rhythm must have some vital property because the fact remains that it does work.

Characteristics of people who stutter

Research has found differences between stutterers and nonstutterers that were evident before the person began to stutter, that is, in childhood (Andrews et al., 1983). The differences, therefore, could not be attributed to many years of stuttering.

Four investigations of school children (Andrews \& Harris, 1964, 2 studies; Okasha, Bishry, Kamel, \& Hassan, 1974; Schindler, 1955) found that stutterers scored significantly lower than nonstutterers on intelligence tests. This led to the prediction that more educational difficulties should be shown by stutterers than their classmates. In fact, it was shown that they do lag approximately 6 months behind their peers in achievement (Andrews et al, 1983).

Andrews et al. (1983) cite six studies showing that stutterers are later in passing their speech milestones than nonstutterers (Andrews \& Harris, 1964, 2 studies; Berry, 1938; Darley, 1955; Johnson, 1959; Morley 1957). Again, the lag may be about 6 months. Andrews et al. (1983) report that stutterers perform more poorly than nonstutterers on some tests of language, such as the Peabody Picture Vocabulary Test, and length of utterance and complexity. 
Nippold (1990) argues that only small differences were shown in these studies and that other data was gathered by parental interview, a subjective method at best. She feels that with data being of questionable validity, there is no convincing evidence that stutterers as a group are delayed. To help settle this debate, perhaps future research should employ the use of more standardized instruments in examining language onset of stutterers.

Andrews et al. (1983) determined through review of seven studies (Andrew \& Harris, 1964, 2 studies; Darley, 1955; Johnson, 1959; Morley, 1957; Schindler, 1955; Williams \& Silverman, 1968) that stutterers are three times more likely to have articulation disorders than nonstutterers. Both Darley (1955) and Andrews \& Harris (1964) questioned parents about additional speech problems their dysfluent children may have had. Darley found that $26 \%$ of the stutterers and $4 \%$ of the nonstutterers had an additional speech problem while Andrews and Harris found that 298 of the stutterers and $10 \%$ of the nonstutterers had histories of additional speech problems. Data from both of these studies show statistically significant differences. A survey of speech-language pathologists supports these findings with articulation being the most frequent concomitant problem, followed by language disorder (Blood \& Seider, 1981). More recently, an increase of interest in the speech motor aspects of stuttering has been shown. Physiological 
differences, as measured by electromyography (EMG), have been found between stutterers and nonstutterers (Van Lieshout, Peters, Starkweather, \& Hulstijn, 1993). High levels of muscle activity are shown with people who stutter (Murray, Empson, \& Weaver, 1987). In addition to this, longer durations of EMG activity were found with stutterers (Guitar et al., 1988) which may fit with the general notion of timing problems found with stutterers (Van Lieshout, Peters, Starkweather, \& Hulstijn, 1993). It is possible that either speech motor control strategies are used by stutterers to handle timing difficulties found in the structure of speech production or that they suffer from a disorder of timing. This remains unclear and provides further impetus for studying differences between stutterers' and nonstutterers' rhythm and timing capabilities.

Several studies have shown that stutterers are poorer on time discrimination than nonstutterers. Hall and Jerger (1978) assessed central auditory discrimination and found that stutterers performed lower on three procedures (acoustic reflex amplitude function, synthetic Identification with Ipsilateral Competing Message, and Staggered Spondaic Word Test) indicating a subtle central auditory deficiency. Toscher and Rupp (1978) also found that stutterers performed lower than nonstutterers on the Ipsilateral Competing Message procedure, indicating a difference in central auditory processing. Kramer, Green 
and Guitar (1987) found differences between stutterers and nonstutterers on a test for Masking Level Differences (MLD) where stutterers produced significantly poorer MLD's than nonstutterers. Since this task requires the detection of a signal in noise, the results of this study suggest that stutterers may have a deficit in temporal processing.

In complex auditory tasks, stutterers are poorer than nonstutterers in stimulus recognition and recall (Andrews et al., 1983). Pinsky and McAdam (1980) found a significant trend for stutterers to have more difficulty recognizing and recalling stimulus words in dichotic listening tasks.

Research shows that basic differences between stutterers and nonstutterers may exist. As a group, stutterers seem to differ in IQ distribution, may begin talking later with more articulation problems, have different speech motor control strategies (whether innate or learned), may have poorer time discrimination in central auditory processing, and seem to have difficulties with recognition and recall of stimulus words in complex auditory tasks. Another basic difference between stutterers and nonstutterers may be in timing and rhythmic abilities which could be associated with their achieving fluency after applying rhythm and timing techniques. This warrants further study. History of rhythmic techniques

The use of rhythm in stuttering therapy has been 
documented from the beginning of the 19th century (wingate, 1976). Colombat de l'Isere is the name most often associated with rhythm use during this period. In spite of his serious commitment to the field of stuttering, references to him are accompanied by an air of ridicule due to his use of rhythm in treating stuttering. In addition to his use of time-beating, Colombat developed a "muthonome," or early metronome-like device. Others used time-beating during this period but did not receive the same recognition. The use of rhythm in treating stuttering waned after Colombat's time. Although the actual reasons are not fully known, it is probably caused by various factors including the advent of surgical treatment and the introduction of other methods.

About one hundred years later, Van Dantzig (1940) revived rhythm techniques in Holland. He introduced a "new method" of syllable-tapping which consisted of speaking in syllables to the accompaniment of sequential taps of the fingers of one hand. Van Dantzig had hopes of American speech pathologists trying it and corresponding with him about their experiences. Apparently his syllable-tapping technique was given little notice in America, possibly due to professional prejudice (Ham, 1986).

Again, the use of rhythm techniques declined until the early 1960's when rhythm began appearing in the stuttering literature. Wingate (1976) states that the attention came 
from outside the United States with interest in the U.S. expressed mostly by people outside the Speech Pathology profession. The prime motivation of this resurgence of interest in rhythm was attributed to Meyer and Mair's (1963) development of an electronic metronome to be worn behind the ear.

Rhythmical procedures may have served to compensate for stutterers' lack of rhythm and timing abilities that may not be lacking in nonstutterers. Other studies investigating differences such as intelligence, personality factors, and speech and language development between stutterers and nonstutterers were appearing in the 50's and 60's (Andrews, et al., 1983) but no studies were done examining rhythmic differences.

Wider development of rhythm use in Europe and England followed (Beech, 1967). The distraction explanation (in which a stutterer supposedly doesn't anticipate difficulty speaking while being "distracted" by a random, arrhythmic beat) was rejected. Brady (Brady \& Brady, 1972) developed an improved Meyer and Mair prototype in 1968 that was a self-contained behind-the-ear instrument. Brady felt that fluency was not maintained when the metronome was no longer present. The carry-over problem was therefore solved as long as the stutterer always had his or her instrument. In a study conducted by Brady and Brady (1972) twenty-six subjects were treated with this device with twenty-one 
showing significant improvement. Seventeen of the twentyone maintained their increased fluency during a follow-up period ranging from 16-54 months. Despite these successes, Brady's reports still had little impact on American methods of treating stuttering.

The treatment of stuttering began to change directions in the 1960's and 1970's when rhythm therapy evolved into "behavior therapy." This occurred when some of the behaviorists transformed rhythm techniques into programmed sequences (Ingham \& Andrews, 1973; Jones \& Azrin, 1969). The changes occurring are now "conditioned" and fluency is "shaped" (Wingate, 1976).

Although rhythm has been used with stutterers for centuries, there is a lack of research on rhythmic speech treatment during the 1960's and 1970's. Very few clinicians chose to investigate it, perhaps because of the quackery associated with it in earlier times. Another problem with rhythm treatment was that rhythm induced fluency but resulted in abnormal speech patterns such as abrupt initiation and termination of syllables and slower than normal rhythm rates (Ham, 1986). However, "naturalness" was being studied by people such as Mallard and Mayer (1979) who advised clinicians to promote more natural speech by not allowing the transfer of slow rhythm rates to outside speaking situations. Jones and Azrin (1969) found that the "naturalness" of speech increased during metronome use when 
the stimulus duration increased up to durations of about 2 seconds, then decreased. This aligned more closely with the rhythms of "normal" speech. Perhaps the stutterers had inherent rhythmic deficiencies that were overcome by the temporary rhythmic "training" of the metronome.

Through the years, rhythm as treatment vacillated between quackery and respectability and its use ebbed and flowed. Historically, rhythm techniques have been used successfully in the forms of "syllable-tapping" methods, metronome methods, and more recently as programmed sequences. The point remains that it can be used as a single method or a collection of methods that quickly and easily induces fluency. In view of these successes, further investigation of music and rhythm skills, using a standardized instrument such as the seashore Measures of Musical Talents, is warranted. Having normative data on musical abilities of stutterers, particularly rhythmic and timing abilities, would lend more credibility to the use of rhythm and timing techniques in the treatment of stuttering. Studies investigating rhythm

Many studies have dealt with stuttering patterns and the application of artificial pacing effects and their positive effects on stuttering. Researchers have not investigated differences between the rhythm and timing capabilities of stutterers and nonstutterers. Perhaps the success rates shown in some of the following studies are due 
to rhythmic techniques that compensate for stutterers' rhythm and timing deficits.

Cooper and Allen (1977) studied timing control accuracy in 10 normal speakers, 5 stutterers receiving treatment, and 5 stutterers dismissed from treatment. Temporal accuracy was measured using speech samples consisting of repeated sentences, paragraphs, and nursery rhymes, with a fingertapping task included as a control. They found a wide range of timing abilities in both stutterers and nonstutterers, but on most of the experimental tasks, normal speakers possessed more accurate timing abilities than stutterers. They also found that the stutterers released from therapy had more accurate timing abilities than the stutterers still in treatment. Cooper and Allen concluded that stuttering may be related to poorer basic timing ability or that stutterers may be slower or less efficient in formulating timing programs for their utterances. Since the Cooper and Allen study did not make use of a standardized instrument, the use of a standardized test, such as the seashore Measures of Musical Talents, Revised, may provide normative data to support these findings and thus further justify the use of rhythm/timing techniques in the treatment of stuttering.

Kent (1983) presented a brief review of neuropsychologic perspectives on stuttering and stated that the central disturbance in stuttering may be a reduced 
ability to generate temporal patterns, whether for sensory or motor purposes, but especially the latter. Kent provides the simplified definition of stuttering as an impairment in the rhythm or fluency of speech. Stuttering may therefore be understood as a disorder of the temporal regulation of speech. Similar to Cooper and Allen's conclusions, stutterers may have an inherent weakness in the planning, timing and control of speech.

Investigating rhythm use in stutterers was not undertaken until the 1960's. Azrin, Jones, and Flye (1968) investigated the dominance of applied rhythm and reported that manual bar pressing or vocalizations in the presence of a regular stimulus beat became synchronized with the ongoing stimulus rhythm. They reported a 908 reduction of stuttering for each subject during the synchronization period. The effect continued for extended periods of spontaneous speech and was attributed to the rhythmic stimulus and not to other factors.

Similarly, Hutchinson and Norris (1977) studied the effect of rhythmic pacing, delayed auditory feedback (DAF) and high intensity masking noise on the frequency of stuttering behaviors. All three auditory stimuli reduced stuttering during reading, but only the metronome produced significant reductions in stuttering during conversational speech.

Coppola and Yairi (1982) studied the effects of 
rhythmic speech training with preschool stuttering children. Their study principally demonstrated that rhythmic speech can be taught to preschool stuttering children as young as 3 years using a desktop metronome, resulting in significant reductions in stuttering.

In view of these findings, it appears that rhythmic training may have a positive effect on the reduction of stuttering. It is possible to teach rhythmic speech, and if rhythm and timing techniques were practiced daily, much as a musician practices techniques applicable to her/his instrument regularly, an ongoing improvement might be observed in rhythm/timing abilities and in more extended periods of spontaneous speech. A standardized testing instrument, such as the Seashore, could be used to determine pretesting baselines and posttesting improvement in rhythm and timing.

Martin and Haroldson (1979) studied the effects of five experimental treatments on stuttering. The five treatments consisted of: time-out (TO), delayed auditory feedback (DAF), "wrong" (in which the word "wrong" was delivered at the moment of stuttering), and metronome. The amount of stuttering decreased significantly in all conditions with the TO condition being the best, followed by the metronome condition. Both were significantly better than the other conditions. Again, these results support the use of rhythm in achieving fluency. Results of this study also 
demonstrate the temporary nature of the reduction in stuttering brought about by a comparatively brief exposure to an experimental treatment. Longer exposure to treatment (in this case, a rhythmic procedure) may, again, result in improved rhythmic capabilities. The use of a standardized instrument (the seashore) could identify stutterers that have perceptual rhythm/timing deficiencies, and therefore possible production deficits. This identification might allow treatment to focus immediately on teaching rhythm techniques that may produce fluency, rather than on treatments that may be less effective.

Harrington (1988) proposes a model of stuttering and delayed auditory feedback (DAF) based on a model of fluent speech whereby a rhythmic structure predetermines the intervals between vowels of stressed syllables. This structure allows a prediction to be made regarding when auditory perception of stressed syllables and their vowels takes place. It is possible that an incorrect prediction is made regarding when the vowel will be perceived relative to its production, in both stuttered and DAF speech.

Hayden, Adams and Jordahl (1982b) studied the effects of pacing and masking on stutterers' and nonstutterers' speech initiation times (SIT). Results showed that both groups improved their SIT's with pacing but had slower SIT's when the masking condition was used. In a companion study, Hayden et al. (1982a) found that voice initiation times 
(VIT) were significantly improved with pacing and with masking and that rhythm VIT was significantly faster than during masking. In other words, dysfluency was significantly reduced during noise and rhythmic stimulation, with the reduction during rhythmic stimulation being greater than the reduction during conditions of noise. Again, rhythm is demonstrated as the condition most improving dysfluency.

Research suggests that stutterers may have some inherent differences in timing capabilities than nonstutterers. They also tend to decrease stuttering or induce fluency quickly and expediently with timing/rhythmic techniques. However, none of the cited studies used a standardized instrument to determine whether there were significant rhythmic/timing deficiencies. A study using the Seashore Measures of Musical Talents, Revised may provide further support for these previous findings by supplying standardized data while simultaneously providing a possible means for easy detection of rhythmic deficiencies in stutterers.

Compared with other methods of treatment, rhythmic pacing techniques (especially the metronome), seem to be the most efficacious in reducing stuttering. It is possible that stutterers lack the necessary rhythm/timing skills that nonstutterers possess, and with the proper training and practice in these skills, they may achieve fluency. Using 
the Seashore prior to treatment may enable a clinician to apply more efficacious treatment in deficient rhythmic/timing areas.

Research is warranted in the study of basic skills of people who stutter. Musical components, particulary rhythm and timing procedures, are an area that has yet to be examined in a systematic fashion. No studies exist that investigate the theory that stutterers have perceptual rhythmic/timing deficiencies. Studies such as this would provide normative data on perceptual musical abilities of stutterers.

The utility of this study is also justified by the wide-spread use of timing and rhythm techniques for the treatment of stuttering. These are techniques that enhance the production of fluent speech. Again, if deficits are shown in the perception of rhythm and timing, deficits may also be shown in the production of these. Therefore, the research question for this study is: do stutterers differ significantly from nonstutterers in perceptual musical abilities, particularly in the area of rhythm? 
CHAPTER III

METHODS AND PROCEDURES

Subjects

Two groups of subjects $(\mathrm{N}=20)$ were utilized in this study; stutterers (10), and nonstutterers (10), which were gathered from the Portland state University speech and Hearing Clinic and stuttering support groups in the summer and fall of 1994, and winter and spring of 1995. Clients previously identified during initial clinic sessions as moderate or greater in severity on Riley's (1972) stuttering Severity Instrument (SSI) constituted the group labeled "stutterers" (see Table 1). The nonstutterers were recruited from classes at Portland State University and local elementary, middle and high schools in the fall of 1994, and winter and spring of 1995. Subjects were free of any other speech and hearing disorders as determined through informal speech and hearing screenings prior to the formal test administration. Normal intelligence was assumed through school and work performance. 
Table 1

Severity Rating for the Group Labeled Stutterers According to Riley's Stuttering Severity Instrument

\begin{tabular}{|c|c|c|c|c|c|}
\hline subject & S Age & NS Age & SSI & Score & ssI Severity \\
\hline 1 & $16: 10$ & $16: 7$ & & 27 & moderate \\
\hline 2 & 38 & 38 & & 31 & moderate \\
\hline 3 & 30 & $30: 9$ & & 25 & moderate \\
\hline 4 & $15: 7$ & $14: 11$ & & 28 & severe \\
\hline 5 & $9: 11$ & $9: 2$ & & 23 & moderate \\
\hline 6 & $27: 8$ & $27: 10$ & & 26 & moderate \\
\hline 7 & 18 & $18: 10$ & & 32 & severe \\
\hline 8 & $13: 10$ & $13: 11$ & & 29 & severe \\
\hline 9 & $17: 1$ & $17: 10$ & & 31 & moderate \\
\hline 10 & 26 & 26 & & 26 & moderate \\
\hline
\end{tabular}

Since the testing materials being used were designed for fourth-grade students and older, the subjects were at least 9 years old. A matched group design using age and gender as the matching variables was implemented with nonstutterer ages remaining within twelve months of stutterer ages. 
Materials

Levels of perceptual musical function were assessed using the Seashore Measures of Musical Talents, Revised (Seashore, Lewis \& Saetveit, 1960). The test consists of a cassette tape and manual. A cassette tape player of good quality is necessary for administration. Calibration was achieved by setting the loudness level of the tape at $70 \mathrm{~dB}$ $\mathrm{SPL}$, in each corner of the room as measured by a LarsonDavis, model 712 , sound level meter. Each subject was screened for adequate hearing using a pure-tone audiometric hearing test at $20 \mathrm{~dB}$. Additionally, the use of answer sheets, scoring key and manual was necessary. Instrumentation

A portable Beltone pure tone audiometer, model 120 , with Beltone TDH 39 headphones was used to conduct the audiometric-hearing screening. A Sony digital audio cassette player with self-contained amplifier and speakers, model CFD-8, was used for test administration. A LarsonDavis sound level meter, model 712, was used for calibration.

The Stuttering Severity Instrument (SSI) (Riley, 1972) was used to identify subjects for the stuttering group. The number of words stuttered and the number of total words spoken are computed during reading or conversation. Percentage of stuttering is computed and converted to a corresponding task score. The three longest blocks are 
averaged and converted into a task score. Lastly, physical concomitant behavior is rated. Frequency, duration and physcial concomitant task scores are then combined for a total score. Normative data is provided in the test manual for comparison. Stuttering severity may be described as very mild, mild, moderate, severe, or very severe in this manner.

The Seashore Test of Musical Talents, Revised, (Seashore, 1960) was used to measure perceptual musical abilities. This test provides separate measures for six musical capacities: pitch, loudness, rhythm, time, timbre, and tonal memory. Test administration is described in the Procedure section.

Normative data for the Seashore is presented for three educational levels (grades 4-5, grades 6-8, and grades 916). Norms were obtained using over 4,000 students which were recruited from a variety of geographical locations throughout the United States. The authors state that although norms are presented only for various educational levels, the tests have been successfully used with adults. Normative data using adults would be useful for research done in the future.

$\underline{\text { Reliability }}$

The reliability of the Seashore Measures of Musical Talents was estimated by means of internal consistency coefficients. The coefficients of reliability are as 
follows: Pitch-.84, Loudness-.74, Rhythm-.64, Time-.71, Timbre-.68, Tonal Memory-.83. These data were collected from high school students in twelve public schools and indicate a high level of stability.

Validity

The authors (Seashore, Lewis \& Saetveit, 1960) state that internal validity is well established and that the tests truly measure the specific abilities they were designed to assess.

\section{Procedure}

The six sections of the Seashore Measures of Musical Talents are labeled Pitch, Rhythm, Loudness, Time, Timbre, and Tonal Memory. All six subtests were administered to the group of stutterers individually during individual clinic appointments. The nonstutterers completed the experimental task in the same fashion.

The test was administered in a room free of distractions with no noise disturbances either in the room or adjacent areas. A sound level meter was used to measure ambient noise levels to provide information regarding noise level conditions in the classroom or clinic room. Ambient noise levels did not exceed $30 \mathrm{~dB}$ SPL. The cassette player was played in the room prior to testing to assure that the volume, clarity, etc. were satisfactory.

After the subject(s) were properly seated, it was explained that this is a test to measure some aspects of the 
ability to hear sounds which occur in music, speech, and many other practical activities. The test was then administered according to the directions in the manual.

In the Pitch test, fifty pairs of tones on a record or cassette tape were presented. The subjects determined whether the second tone was higher (H) or lower (I) than the first. A mark was then made in either a column headed $\mathrm{H}$ or L. The Time test required the subject to determine whether the second tone was longer (L) or shorter (S) than the first. Again, there were fifty trials and a mark was made in either the column headed L or S. Fifty pairs of notes are given in the Timbre test and the subjects determined whether the tone color was the same (S) or different (D). A mark was made in either the $s$ column or the $D$ column. In the Rhythm test, there were short pulses of pure tones comprising 10 pairs of five note patterns, 10 pairs of six note patterns, and 10 pairs of seven note patterns. The subjects determined if the first set of pure tones played was rhythmically different from the second set and marked either S (same) or D (different) in the appropriate column. The Tonal Memory test consists of 10 pairs of three note patterns, 10 pairs of four note patterns, and 10 pairs of five note patterns. The subjects determined if the first pair played is tonally different from the second pair played, for each category. Again, either S (same) or D (different) was marked. The Loudness test is based on 50 
pairs of pure tones with subjects determining which tone is louder or softer. The subject marked in either a column headed $\mathrm{S}$ for stronger or $\mathrm{W}$ for weaker. A total score of level of musical function was then determined from the summed scores of each subtest. The six subtests took approximately one hour to complete including time allotted for complete test instructions and demonstration. 


\section{CHAPTER IV}

\section{RESULTS AND DISCUSSION}

\section{Results}

The purpose of this study was to determine if there was a significant difference in the perceptual musical abilities of stutterers versus the perceptual musical abilities of nonstutterers as measured by the Seashore Measures of Musical Talents, Revised (1960). A matched group design using age as the independent variable was implemented. All six subtests of the test were administered: Pitch, Rhythm, Loudness, Time, Timbre, and Tonal Memory. In addition, an overall test score was also used for comparative purposes. Group mean scores are shown in Table 2. Stutterers' scores are lower than nonstutterers' scores in each subtest and in total scores. 
Table 2

Group Mean Raw Scores, Standard Deviations, and Ranges for

\section{Subtests and Total scores}

\begin{tabular}{llll}
\hline Variable & $\begin{array}{l}\text { Mean Score for } \\
\text { Stutterers } / \\
\text { Nonstutterers }\end{array}$ & $\begin{array}{l}\text { SD for } \\
\text { Stutterers/ } \\
\text { Nonstutterers }\end{array}$ & Range \\
\hline Pitch & $34.9 / 41.7$ & $11.59 / 5.33$ & $21-48$ \\
Loudness & $43.6 / 45.2$ & $6.78 / 4.39$ & $29-49$ \\
Rhythm & $26.0 / 29.3$ & $1.49 / 3.05$ & $24-37$ \\
Time & $42.6 / 44.3$ & $4.45 / 4.52$ & $33-50$ \\
Timbre & $40.8 / 41.6$ & $2.30 / 3.83$ & $36-47$ \\
Tonal Memory & $19.3 / 23.6$ & $8.23 / 4.08$ & $8-30$ \\
Total & $209.2 / 225.7$ & $23.97 / 16.52$ & $163-247$ \\
\hline
\end{tabular}

A Wilcoxon Signed Rank Test for Paired Observations was used $(P<.05)$ to estimate the probability that the differences between the two independent groups could have occurred by chance. Scores were represented using an interval scale of measurement with one score for each subject in each group. A nonparametric test (Wilcoxon Signed Rank Test for Paired Observations) was utilized since group sizes consisted of 10 and it could not be expected that distribution would be normal. The results are summarized in Table 3 . 
Table 3

Wilcoxon Matched Pairs Signed Ranks Test Comparing

Perceptual Musical Ability of Stutterers and Nonstutterers

\begin{tabular}{lc}
\hline Variable & $\begin{array}{c}2 \text {-Tailed } \\
\text { Probability } \\
\mathrm{P}=\end{array}$ \\
\hline Pitch & 0.0593 \\
Loudness & 0.6356 \\
Rhythm & 0.0077 * \\
Timing & 0.3980 \\
Timbre & 0.6784 \\
Tonal Memory & 0.1536 \\
Totals & $0.0244 *$ \\
\hline Significant difference &
\end{tabular}

* Significant difference

Results show significant differences between the stutterers' group and the matched nonstutterers' group in the rhythm subtest $(P=.0077)$. Results for the total score also revealed significant differences between the stutterers' group and the nonstutterers' group $(P=.0244)$. None of the other subtests from the Seashore Measures of Musical

Talents, Revised (1960) reached the .05 level of significance between the two groups.

Discussion

The results of this study indicate that differences exist between stutterers and nonstutterers in perceptual musical abilities for this group of subjects, as measured by the Seashore Measures of Musical Talents (Seashore, 1960). This is shown by the stutterers' significantly different 
total scores and significantly different rhythm subtest scores (see Table 3 ). It is possible that the significant total score difference may be due to the difference in the rhythm subtest scores. Total score differences might also be attributed to a cumulative affect and not because there is an actual difference in the overall perceptual musical abilities between stutterers and nonstutterers. However, stutterers may actually possess a perceptual rhythmic difference.

These findings contribute to the existing body of literature which also show differences between stuttering and nonstuttering groups. Prior studies of school children found that stutterers scored significantly lower than nonstutterers on intelligence tests (Andrews \& Harris, 1964; Okasha, Bishry, Kamel, \& Hassan, 1974; Schindler, 1955). Other studies have shown that stutterers are later in passing speech milestones than nonstutterers (Andrews and Harris, 1964, 2 studies; Berry, 1938; Darley, 1955; Johnson, 1959; Morley, 1957), and that stutterers perform more poorly on some tests of language, and length of utterance and complexity (Andrews et al., 1983).

Another aspect in which stutterers may be different from nonstutterers may be in stutterers' reduced ability to generate temporal patterns, especially for motor purposes (Kent, 1983). Kent provided a simplified definition of stuttering as an impairment in the rhythm or fluency of 
speech. The results of the rhythm subtest on the seashore test indicate that a perceptual rhythmic impairment may exist as well. If a person has difficulty perceptually recognizing differences between rhythmic patterns, then the production of correct rhythmic speech patterns might be extremely difficult.

Another study investigating timing control accuracy in stutterers and nonstutterers was done by Cooper and Allen (1977). A variety of speech samples were used in finding that normal speakers possessed more accurate timing abilities than stutterers. They concluded that stuttering may be a manifestation of poorer basic timing ability or that stutterers may be slower or less efficient in formulating timing programs for their utterances. However, no standardized instrument was used, so no normative data resulted. The results of the rhythm subtest of the seashore Test in this study may now provide initial data that their study was not able to provide. The rhythm subtest is, again, a perceptual measure. If perceptual difficulties are present, then production difficulities may result. This may support their conclusion that poorer rhythm and timing abilities play a role in stuttering.

Recent studies using technology lend support to Kent's simplified definition of stuttering as a rhythm impairment. Studies using electromyography (EMG) involving the speech motor aspects of stuttering show physiological differences 
between stutterers and nonstutterers (Guitar et al., 1988; Murray, Empson, \& Weaver, 1987; Van Lieshout et al., 1993). It has been unclear whether these physiological differences are speech motor control strategies used by stutterers to handle timing difficulties found in the structure of speech production or that they suffer from an impairment of rhythm production, or both. Results of this study would support the impairment theory or a combination of impairment and compensation, and not the notion that stutterers are only using compensatory strategies.

Previous research studying timing elements of stuttering seemed to indicate possible disorders of timing in stutterers (Cooper \& Allen, 1977; Kent, 1983). It was therefore predicted that the stutterers would also score significantly differently on the time subtest of the Seashore. However, the results did not show significant differences. Rhythm and timing are strongly related and to separate one from the other for testing purposes is very difficult, if not impossible. The time test consisted of listening to two tones and determining whether the second tone is longer or shorter than the first. This may actually be considered a subtest of perceptual duration and by itself may not have been a sensitive enough measure. The rhythm subtest consisted of listening to two series of tones and determining whether the first set of tones played is rhythmically different from the second set. For differences 
to occur, individual notes would need to be different in length, or time. A more sensitive timing element was therefore contained within the rhythm subtest.

The results of this study indicate that for this group of subjects there is a difference between stutterers and nonstutterers. This difference is of basic perceptual musical ability, particularly in the area of rhythm. In order to generalize these findings to the general population, a larger sample size must be collected. Future research should include stutterer and nonstutterer sample sizes that are significantly larger. This would provide a broader base of data that has not been previously available. 


\title{
CHAPTER V \\ SUMMARY AND IMPLICATIONS
}

\begin{abstract}
Summary
Previous research has indicated that rhythm has been used successfully as a single method or a collection of methods that quickly and easily induces fluency (Ham, 1983; wingate, 1976). In spite of these successes, little research has been done with regard to stutterers' musical ability. Research has shown that basic differences between stutterers and nonstutterers may exist in areas of intelligence (Andrews \& Harris, 1964, 2 studies; Okasha et al., 1974; Schindler, 1955), speech and language development (Andrews \& Harris, 1974, 2 studies; Berry, 1938; Darley, 1955; Johnson, 1959; Morley, 1957), speech motor control strategies (Guitar et al., 1988; Murray et al., 1987; Van Lieshout et al., 1993), time discrimination in central auditory processing (Hall \& Jerger, 1978; Kramer, Green \& Guitar, 1987; Toscher \& Rupp, 1978), and in recognizing and recalling stimulus words in complex auditory tasks (Andrews et al., 1983; Pinsky \& McAdam, 1980). Possible differences between stutterers and nonstutterers in musical ability has not been studied.
\end{abstract}

The purpose of this study was to determine whether 
there was a difference between the perceptual musical abilities of stutterers versus nonstutterers as measured by the Seashore Measures of Musical Talents, Revised (1960). Two groups of subjects consisting of 10 stutterers and 10 nonstutterers were tested using the seashore test. They were matched according to age and gender. The stutterers had previously been identified as at least moderate in severity on Riley's (1972) Stuttering Severity Instrument (SSI). The Wilcoxon Signed Rank Test for Paired Observations was used to estimate the probability that the two independent groups could have occurred by chance. Scores of individual subtests were also compared using Wilcoxon Signed Ranks to determine whether there were differences between groups in specific areas.

Results show stutterers scoring significantly lower in the rhythm subtest and in total scores. Other significant differences were not found. This resulted in the rejection of the null hypothesis. This would indicate that stutterers' and nonstutterers' scores on the seashore Measures of Musical Talents, Revised are not significantly different. The null hypothesis indicates no difference in musical abilities between the two groups.

$$
\text { Implications }
$$

\section{Research}

This study seems to be the first of its kind in attempting to identify differences in musical ability 
between stutterers and nonstutterers. In order to lend more support to the findings of this study, several research possibilities exist.

One possibility is to continue to use the seashore to test a larger number of subjects. Significant results were obtained using groups of 10, however, larger group sizes may affect the outcome of future studies and lend increased validity to the findings of this study.

Another possibility is to conduct a preliminary background survey, particularly in the area of previous musical study. Failing to include those who have had significant musical training would eliminate the possibility that musical training could affect the outcome of the study. School-age subjects could be matched in the future for school district and grade. This would help to assure that any previous musical training would be consistent within matched pairs.

The differences shown in this study were perceptual rhythmic and musical differences. Future research could focus on the production of various rhythmic patterns and sequences to determine whether differences exist between stutterers' and nonstutterers' abilities to produce a variety of rhythms. However, correlations between comprehension and production tasks should be studied to determine whether a relationship truly exists between the perception of rhythm and the production of rhythm. The 
issue of how analagous rhythm comprehension tasks and rhythm production tasks are should be investigated.

\section{clinical}

If the results from the Seashore suggest perceptual rhythmic deficiencies, perhaps treatment should focus on methods using rhythm instead of other techniques that may not address the deficiency directly. Since the seashore is simple to administer, it could actually be used as a pretest and posttesting device. If a correlation exists between perceptual rhythmic deficiencies and stuttering, rhythmic techniques could be taught and progress measured.

Due to the small sample size, the results of this study can only be related to this group and cannot be generalized to the population. However, these results indicate that this group of stutterers have different perceptual musical capabilities than nonstutterers in general, and different perceptual rhythmic abilities in particular. These findings coincide with other differences found between stutterers and nonstutterers described by Andrews et al. (1983), Berry (1938), Darley (1955), Guitar et al. (1988), Murray et al. (1987), Okasha et al. (1974), Van Lieshout et al. (1993), and others. The seashore test was a simple measure for use in obtaining these results and provides more information in studying differences between stutterers and nonstutterers. 
Andrews, G., Craig, A., Feyer, A., Hoddinott, S., Howie, P.,\& Neilson, M. (1983). Stuttering: A review of research findings and theories circa 1982. Journal of Speech and Hearing Disorders, 48, 226-246.

Andrews, G., \& Harris, M. (1964). The syndrome of stuttering. Clinics in Developmental Medicine, 17. London: Heinemann.

Apel, W., \& Daniel, R. T. (1960). The Harvard brief dictionary of music. New York: Simon and Schuster.

Azrin, N., Jones, R. J., \& Flye, B. (1968). A synchronization effect and its application to stuttering by a portable apparatus. Journal of Applied Behavior Analysis, 1, 283-295.

Barber, V. (1940). Studies in the psychology of stuttering: XV. Rhythmsas1a asatzabtion in stuttering. Journal of Speech Disorders, $\underline{5}, 29-$ 42 .

Beech, H. R. (1967). Stuttering and stammering. Psychology Today, $1,48-51$.

Berry, M. (1938). The developmental history of stuttering children. The Journal of Pediatrics, 12, 209-217.

Blood, G. W., \& Seider, R. (1981). The concomitant problems of young stutterers. Journal of Speech and Hearing Disorders, 46, 31-33.

Bloodstein, o. (1949). Conditions under which stuttering is reduced or absent: A review of the literature. Journal of Speech and Hearing Disorders, 14, 295-302.

Bluemel, C. S. (1960). Concepts of stammering: A century in review. Journal of speech and Hearing Disorders, 25, 24-32.

Brady, J. P., \& Brady, C. N. (1972). Behavior therapy of stuttering. Folia Phoniatrica, 24, 355-359.

Cassidy, J. W. (1992). Communication disorders: Effect on children's ability to label music characteristics. Journal of Music Therapy, 29, 113-124.

Cohen, N. S. (1992). The effect of singing production of neurologically impaired persons. Journal of 
Music Therapy, 29, 87-102.

Cohen, N. S., \& Masse, R. (1993). The application of rhythmic instruction as a therapeutic intervention for persons with neurogenic communication disorders. Journal of Music Therapy, 30, 81-99.

Cooper, M. H., \& Allen, G. D. (1977). Timing control accuracy in normal speakers and stutterers. Journal of Speech and Hearing Research, 20, 55-71.

Coppola, V. A., \& Yairi, E. (1982). Rhythmic speech training with preschool stuttering children: An experimental study. Journal of Fluency Disorders, I, 447-457.

Darley, F. L. (1955). The relationship of parental attitudes and adjustments to the development of stuttering. In $W$. Johnson \& $R$. R. Leutenegger (Eds.), stuttering in children and adults (pp. 74153). Minneapolis: University of Minnesota Press.

Guitar, B., Guitar, C., Neilson, P., O'Dwyer, N., \& Andrews, G. (1988). Onset sequencing of selected lip muscles in stutterers and nonstutterers. Journal of Speech and Hearing Research, 31, 28-35.

Hall, J. W., \& Jerger, J. (1978). Central auditory function in stutterers. Journal of Speech and Hearing Research, 21, 324-337.

Ham, R. (1986). Techniques of stuttering therapy. Englewood Cliffs, NJ: Prentice Hall.

Ham, R. (1990). Therapy of stuttering: Preschool through adolescence. Englewood Cliffs, NJ: Prentice Hall.

Harrington, J. (1988). Stuttering, delayed auditory feedback, and linguistic rhythm. Journal of Speech and Hearing Research, 31, 36-47.

Hayden, P. A., Jordahl, N. , \& Adams, M. R. (1982a). Stutterers' voice initiation times during conditions of novel stimulation. Journal of Fluency Disorders, $7,1-7$.

Hayden, P. A., Jordahl, N., \& Adams, M. R. (1982b). The effects of pacing and masking on stutterers' and nonstutterers' speech initiation times. Journal of Fluency Disorders, $7,9-19$. 
Humpal, M. (1991). The effects of an integrated early childhood music program on social interaction among children with handicaps and their typical peers. Journal of Music Therapy, 3 , 161-177.

Ingham, R. J., \& Andrews, G. (1973). Behavior therapy and stuttering: A review. Journal of Speech and Hearing Disorders, $38,405-441$.

Johnson, w. (1959). The onset of stuttering. Minneapolis: University of Minnesota Press.

Jones, R. J., \& Azrin, N. H. (1969). Behavioral engineering: Stuttering as a function of stimulus duration during speech synchronization. Journal of Applied Behavior Analysis, 2, 223-229.

Kent, R. D. (1983). Facts about stuttering: Neuropsychologic perspectives. Journal of Speech and Hearing Disorders, 48, 249-255.

Kramer, M. B., Green, D. , \& Guitar, B. (1987). A comparison of stutterers and nonstutterers on masking level differences and synthetic sentence identification tasks. Journal of Communication Disorders, 20, 379-390.

Mallard, A. R. \& Meyer, L. A. (1979). Listener preferences for stuttered and syllable-timed speech production. Journal of Fluency Disorders, 4, 117-121.

Martin, R., \& Haroldson, S. K. (1979). Effects of five experimental treatments on stuttering. Journal of Speech and Hearing Research, 22, 132-146.

Meyer, V., \& Mair, J. M. M. (1963). A new technique to control stammering. Behavioral Research Therapy, 1. 751-754.

Morley, M. E. (1957). The development and disorders of speech in childhood. Edinburgh: Livingstone.

Murray, K. S., Empson, J. A. C., \& Weaver, S. M. (1987). Rehearsal and preparation for speech in stutterers: A psychophysiological study. British Journal of Disorders of Communication, 22 , 145150 .

Nippold, M. A. (1990). Concomitant speech and language disorders in stuttering children: A critique of the literature. Journal of Speech and Hearing 
Disorders, 55, 51-60.

Okasha, A., Bishry, Z., Kamel, M., \& Hassan, A. H. (1974). Psychosocial study of stammering in Egyptian children. British Journal of Psychiatry, $124,531-533$.

Pinsky, S. D., \& McAdam, D. W. (1980).

Electroencephalographic and dichotic indices of cerebral laterality in stutterers. Brain and Language, 11, 374-397.

Riley, G. D. (1972). A stuttering severity instrument for children and adults. Journal of Speech and Hearing Disorders, 37, 314-322.

Seashore, C. E. (1919). The psychology of musical talent. Boston: Silver Burdett.

Seashore, C. E., Lewis, D., \& Saetveit, J. G. (1960). Manual of instructions and interpretations for the Seashore Measures of Musical Talents (revised). New York, NY: The Psychological Corporation.

Schindler, M. A. (1955). A study of educational adjustments of stuttering and nonstuttering children. In $\mathrm{w}$. Johnson and $\mathrm{R}$. Leutenegger (Eds.), stuttering in children and adults (pp. 348-357). Minneapolis: University of Minnesota Press.

Sparks, R. W. \& Holland, A. L. (1976). Method: Melodic intonation therapy for aphasia. Journal of Speech and Hearing Disorders, 41, 287-297.

Toscher, M. M., \& Rupp, R. R. (1978). A study of the central auditory processes in stutterers using the Synthetic Sentence Identification (SSI) battery. Journal of Speech and Hearing Research, 21, 779792 .

Van Dantzig, M. (1940). Syllable-tapping, a new method for the help of stammerers. Journal of speech Disorders, $\underline{5}, 127-132$.

Van Lieshout, P. H. H. M., Peters, H. F. M., Starkweather, C. W., \& Hulstijn, W. (1993). Physiological differences between stutterers and nonstutterers in perceptually fluent speech: EMG amplitude and duration. Journal of Speech and Hearing Research, 36, 55-63. 
Van Riper, C. (1973). The treatment of stuttering. Englewood Cliffs, NJ: Prentice Hall.

Williams, D. E. \& Silverman, F. H. (1968). Note concerning articulation of school-age stutterers. Perceptual and Motor Skills, 27, 713-714.

wingate, M. E. (1964). A standard definition of stuttering. Journal of Speech and Hearing Disorders, 29, 484-489.

wingate, M. E. (1976). Stuttering theory and treatment. New York, NY: Irvington Publishers, John Wiley.

Zoller, M. B. (1991). Use of music activities in speech-language therapy. Language, Speech and Hearing Services in Schools, 22, 272-276.2222 